\title{
Concomitant Induction of Apoptosis and Autophagy by Prostate Apoptosis Response-4 in Hypopharyngeal Carcinoma Cells
}

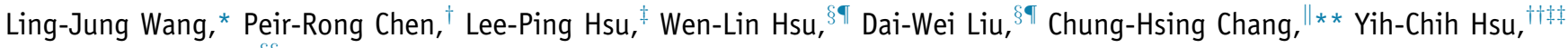 \\ and Jeng-Woei Lee ${ }^{\star \S \S}$
}

\begin{abstract}
From the Institute of Medical Sciences, ${ }^{*}$ the Departments of Otolaryngology ${ }^{\dagger}$ and Life Sciences, ${ }^{\S \S}$ and the School of Medicine, ${ }^{\S}$ Tzu-Chi University, Hualien; the Department of Otorhinolaryngology, ${ }^{\ddagger}$ Buddhist Tzu Chi General Hospital, Taichung; the Department of Radiation Oncology, ${ }^{\circledR}$ Buddhist Tzu Chi General Hospital, Hualien; the Research Center of Excellence for Environment Medicine," and the Department of Dermatology, ** Kaohsiung Medical University, Kaohsiung; and the Department of Bioscience Technology ${ }^{\dagger \dagger}$ and the Center for Nanotechnology, ${ }^{\ddagger}$ Chung Yuan Christian University, Taoyuan, Taiwan
\end{abstract}

Accepted for publication October 24, 2013.

Address correspondence to Jeng-Woei Lee, Ph.D., Department of Life Sciences, Tzu-Chi University, No. 701, Zhongyang Rd, Section 3, Hualien 97004, Taiwan. E-mail: jwlee@mail.tcu.edu.tw.

\begin{abstract}
The tumor-suppressive activity of prostate apoptosis response-4 (Par-4) has been demonstrated in a variety of human cancers. In this study, for the first time to our knowledge, we demonstrated that a higher intensity of Par-4 was significantly correlated with a better response in patients with hypopharyngeal carcinoma undergoing radiotherapy alone or concurrent chemoradiotherapy. Mechanistically, an elevated expression of Par-4 induced apoptosis of hypopharyngeal carcinoma cells and sensitized cells toward chemotherapeutic agents or X-ray irradiation. Along with apoptotic incitation, intriguingly, autophagic flux also increased on Par-4 stimulation and contributed to cell death. Moreover, the expressions of multiple common regulators involved in apoptosis and autophagy were regulated by Par-4. Taken together, our results suggested a prognostic role of Par-4 in hypopharyngeal carcinoma and showed novel activity of Par-4 in apoptosis and autophagy induction. (Am J Pathol 2014, 184: 418-430; http://dx.doi.org/10.1016/j.ajpath.2013.10.012)
\end{abstract}

Hypopharyngeal carcinoma (HPC) (International Classification of Diseases-10 code C12 to 13) is a type of head and neck malignancy. In Taiwan, the age-adjusted incidence rate of HPC has gradually increased in the past two decades from 0.84 per 100,000 individuals in 1990 to 2.94 per 100,000 individuals in 2009. Although surgery, radiotherapy alone or in conjunction with chemoradiation, is the standard treatment for HPC, understanding the molecular mechanisms is necessary for pathophysiological clarification and survival rate improvement. For instance, including p27, cyclin D1, p53, matrix metalloproteinases 2 and 9, Twist, and miRNA has been revealed to have an association with the tumorigenesis and metastasis of HPC. ${ }^{1-7}$ In addition, systemic investigation by microarray analysis and chromosome aberration assessment also paves the way for delineation of HPC carcinogenesis. ${ }^{8-10}$ Of interest, in our previous study, we showed expression of a pro-apoptosis protein, prostate apoptosis response-4 (Par-4), in HPC cases. ${ }^{11}$

Par-4 was originally identified in androgen-independent prostate cancer cells undergoing apoptosis. ${ }^{12}$ It is ubiquitously expressed in various tissue types, and overexpression of Par-4 sufficiently induces apoptosis in cancer cells, but not in immortalized or normal cells. ${ }^{13}$ Par- 4 contains a leucine zipper domain at the carboxy-terminus and two putative nuclear localization signals at the N-terminus. Studies have revealed that phosphorylation of Par-4 determines its activity; for example, $\mathrm{Thr}^{155}$ phosphorylation by protein kinase $\mathrm{A}$ is required for its pro-apoptosis function and, in contrast, modification by Akt (or protein kinase B) restrains the ability of Par-4 to reduce cell survival. ${ }^{14,15}$ Par-4 is able to engage in extrinsic and intrinsic apoptosis pathways. ${ }^{16}$ Intriguingly, new evidence has indicated that the detailed mechanisms by which Par-4 mediates cell death involve intracellular and extracellular action modes; moreover, intracellular Par-4 is also essential for extracellular Par-4-induced apoptosis. ${ }^{17-19}$ In

Supported by the Taiwan National Science Council grant NSC99-2320B-320-014-MY2 and the Taiwan Department of Health grant DOH97-TDI-111-TM017. 
addition, through direct interaction with NF- $\mathrm{BB}$ and inhibition of NF- $\kappa \mathrm{B}$ transcriptional activity, Par-4 alters DROSHA and miRNA expression and, hence, further attenuates $B C L-2$ mRNA translation. ${ }^{20}$ Interestingly, evidence has also demonstrated that Par- 4 is a novel substrate of caspase 3, and a cleaved fragment of Par-4 still retains pro-apoptosis activity. ${ }^{21}$ Remarkably, down-regulation of Par-4 is exhibited in renal cancers, neuroblastoma, acute lymphocytic leukemia, and endometrial cancer, as well as Ras-transformed cells. ${ }^{22-26}$ Consistent with these findings, Par-4 has been shown to be involved in the inhibition of transformation, partly through impingement of Akt activation or topoisomerase 1 catalytic activity. ${ }^{27-30}$ In addition, Par-4-null and Par-4/selective for apoptosis in cancer cells transgenic mice further support the tumor-suppressive ability of Par- 4 in the inhibition of primary tumor growth and metastasis. ${ }^{18,31,32}$ Therefore, Par- 4 is considered as an attractive target for cancer therapy development. ${ }^{16,28,31}$

A non-specific catabolic process, macroautophagy (referred to herein as autophagy), is up-regulated under stress conditions. On various stresses, such as nutrient starvation, hypoxia, or unfolded protein accumulation, autophagy is induced via double-membrane vacuole (autophagosome) formation to engulf aggregate-prone proteins or damaged organelles, which is followed by fusing with lysosomes (autolysosomes) to eliminate cytoplasmic substrates for the recycling of metabolic substances. ${ }^{33}$ Several autophagyrelated proteins (Atgs) and class III phosphatidylinositol 3-kinases (alias PIK3C3 or VPS34) are required for autophagosome completion. Conversely, the activity of the autophagy machinery is negatively modulated by a master regulator of multiple signaling pathways, mammalian target of rapamycin. ${ }^{34}$ Because autophagy plays a cytoprotective role for homeostasis, development, and differentiation, it is inferred to alleviate tumor cell death and attenuate cancer therapeutic efficacy. ${ }^{35,36}$ Paradoxically, genetic and functional analysis has also elucidated the tumor-suppressive activity of autophagy. ${ }^{37}$ Particularly, emerging evidence suggests cross talk between autophagy and apoptosis, including the Beclin 1 and $\mathrm{Bcl}-2 / \mathrm{Bcl}-\mathrm{X}_{\mathrm{L}}$ interaction, caspaseor calpain-mediated Atgs cleavage, and linkage by a molecular hub, p62. ${ }^{38-41}$ Yet, the regulatory mechanisms between autophagy and apoptosis are still elusive.

Extending our previous findings, ${ }^{11}$ in this study, we, for the first time to our knowledge, reported a prognostic role of Par-4 in HPC, and demonstrated a novel pro-apoptosis and autophagy activity of Par-4 through modulation of multiple common regulators, thus enhancing cell death.

\section{Materials and Methods}

\section{Clinical Analysis}

Clinical information from 93 HPC cases, which were diagnosed from January 1991 to December 1999 in Buddhist Tzu Chi General Hospital (Hualien, Taiwan), was collected, ${ }^{11}$ and the patients were followed up for an additional 6 years. The relationships between Par-4 expression ${ }^{11}$ and age, sex, TNM stage, treatment, and therapeutic outcome of HPC cases were analyzed using the SPSS program (SPSS, Inc., Chicago, IL). Permission to use these clinical data for research purposes was obtained from the Research Ethics Committee at Buddhist Tzu Chi General Hospital.

\section{Cell Culture, Plasmids, and siRNA}

Human hypopharyngeal carcinoma cell line FaDu (Bioresource Collection and Research Center number 60214) was purchased from the Bioresource Collection and Research Center (Hsinchu, Taiwan). Cells were cultured in minimum essential medium supplemented with $10 \%$ fetal bovine serum, $1 \mathrm{mmol} / \mathrm{L}$ sodium pyruvate, $50 \mu \mathrm{g} / \mathrm{mL}$ streptomycin, and 50 $\mathrm{U} / \mathrm{mL}$ penicillin at $37^{\circ} \mathrm{C}$ in a $5 \% \mathrm{CO}_{2}$ incubator. Par-4/ pCMV6-XL6 plasmid was obtained as described previously. ${ }^{42}$ For microtubule-associated protein 1 light chain 3 [pGreen Fluorescent Protein (pGFP)-LC3] plasmid construction, LC3 cDNA (provided by Dr. Noboru Mizushima, Tokyo Medical and Dental University, Tokyo, Japan) ${ }^{43}$ was inserted into the BgIII and EcoRI sites of pEGFP-C1 expression vector (Clontech Laboratories, Inc., Mountain View, CA). Plasmid Par-4-GFP, Flag-Beclin 1, and NF- $\kappa \mathrm{B}-$ dependent luciferase reporter (NF- $\kappa \mathrm{B}-\mathrm{luc}$ ) were generously provided by Dr. Ute Preuss (University of Bonn, Bonn, Germany), Dr. Beth Levine (University of Texas Southwestern Medical Center, Dallas), and Dr. Wen-Ling Shih (National Pingtung University of Science and Technology, Pingtung, Taiwan), respectively. ON-TARGETplus SMARTpool siRNA against human Par-4 (L-004434-00-0005) and nontargeting SMARTpool siRNA (D-001810-10 ${ }^{-05}$ ) (Thermo Fisher Scientific, Lafayette, CO) were used for RNA silencing.

\section{Transfection and Western Blot Analysis}

Briefly, cells were placed on 35-mm plates and grown to $60 \%$ to $70 \%$ confluence. Cells were then transfected with Lipofectamine 2000 reagent (Life Technologies Corporation, Carlsbad, CA) and plasmid or siRNA mixture, according to the manufacturer's instructions. After transfection, cells were harvested for Western blot analysis or direct observation by fluorescence microscope. The percentage of GFPLC3 - positive cells with GFP-LC3 dots was calculated as the number of fluorescent punctate cells/the number of GFP-LC3 expression cells. To establish a stable GFP-LC3 expression cell line, cells were transfected with pGFP-LC3 plasmid and fluorescent colonies were picked up via $800 \mu \mathrm{g} / \mathrm{mL}$ G418 selection. For Western blot analysis, cell extracts were prepared as described previously. ${ }^{42}$ Samples were resolved on $10 \%$ to $12 \%$ SDS-polyacrylamide gels and then subjected to immunoblotting with respective antibodies: rabbit anti-Par-4 antibody (Cell Signaling Technology, Beverly, MA), rabbit anti-phosphate Par-4 (Thr163) antibody (Cell Signaling Technology), mouse anti-Akt1 antibody (Cell Signaling 
Technology), mouse anti-phospho-Akt (Ser473) antibody (Cell Signaling Technology), goat anti-phospho-Bcl-2 (Ser87) antibody (Santa Cruz Biotechnology, Santa Cruz, CA), rabbit anti-Bcl-2 antibody (Cell Signaling Technology), rabbit anti-cleaved poly (ADP-ribose) polymerase (PARP) antibody (Cell Signaling Technology), rabbit anticleaved caspase 3 antibody (Cell Signaling Technology), rabbit anti-Atg12 antibody (Cell Signaling Technology), rabbit anti-Atg5 antibody (Epitomics, Burlingame, CA), rabbit anti-LC3B antibody (Cell Signaling Technology), mouse anti-GFP antibody (Santa Cruz Biotechnology), rabbit anti-protein kinase $\mathrm{C}$ (PKC) $\zeta$ antibody (Cell Signaling Technology), and rabbit anti-p62 antibody (Cell Signaling Technology) for 1 hour. After incubation with the appropriate secondary antibody, the bands were visualized using an electrochemiluminescence system (GE Healthcare Life Sciences, Buckinghamshire, UK). The densities of the bands were measured using ImageJ software version $1.47(\mathrm{NIH}$, Bethesda, MD), and values were normalized to the densitometric values of actin in each sample. The fold change in protein amount was then calculated for the experimental sets compared with the control.

\section{Cell Viability Assay}

Briefly, cells were incubated with $0.5 \mathrm{mg} / \mathrm{mL}$ MTT assay (Sigma-Aldrich, St. Louis, MO) in culture medium for 3 hours at $37^{\circ} \mathrm{C}$, and then dimethyl sulfoxide was added to dissolve the formazan crystals. The absorbance at $540 \mathrm{~nm}$ was determined using a Biokinetics plate reader (Bio-Tek Instruments, Inc., Winooski, VT). The percentage of cell viability was calculated as the value of the experimental set/ the value of the control.

\section{TEM Data}

For transmission electron microscopy (TEM) examination of autophagic vacuoles, cell pellets were collected and resuspended in glutaraldehyde solution $(2.5 \%$ glutaraldehyde and $1 \%$ tannic acid in $0.1 \mathrm{~mol} / \mathrm{L}$ cacodylate buffer). After washing with $5 \%$ sucrose in $0.1 \mathrm{~mol} / \mathrm{L}$ cacodylate buffer, cells were postfixed with $1 \%$ osmium tetroxide in 0.1 $\mathrm{mol} / \mathrm{L}$ cacodylate buffer for 1 hour at $4^{\circ} \mathrm{C}$. Samples were dehydrated and embedded with $100 \%$ Spurr's resin for 2 hours at room temperature, and polymerized for 1 hour at $60^{\circ} \mathrm{C}$. Ultrathin sections were made and stained with $2 \%$ uranyl acetate and lead citrate. The sections were visualized using TEM (HITACHI H-7500; Hitachi High-Technologies Corp., Tokyo, Japan) at an accelerating voltage of $80 \mathrm{kV}$.

\section{Flow Cytometry}

To quantify the turnover of GFP-LC3, cells were transfected with pGFP-LC3 plasmid alone, or with either Par-4/ pCMV6-XL6 or Flag-Beclin 1 plasmid in the presence or absence of autophagy inhibitors. At 48 hours after transfection, $1 \times 10^{4}$ GFP-LC3-expressing cells in each sample were harvested and analyzed using an FACScan flow cytometer (BD Biosciences, San Jose, CA), as described previously. ${ }^{44}$ For quantification, the relative fluorescence intensity (percentage) was calculated by dividing the level of GFP-LC3 of each sample/the level of the mock control in the respective experimental set. For quantification of p62, cells were transfected with or without Par-4/pCMV6-XL6 plasmid, and posttransfection after 24 or 48 hours, cells were harvested and fixed with $4 \%$ formalin for 15 minutes at room temperature, then permeabilized with $90 \%$ cold methanol/ PBS for 30 minutes. Subsequently, cells were immunostained using mouse anti-p62 antibody (EMD Millipore Corporation, Billerica, MA), followed by incubation with Alexa Fluor 546 goat anti-mouse IgG (Life Technologies Corporation). A total of $1 \times 10^{4}$ cells were then collected and analyzed using an FACScan flow cytometer, as previously described. The relative fluorescence intensity (percentage) was calculated by dividing the level of fluorescence of overexpressing Par-4 cells/the level of the mock control in the respective experiment. To measure the percentage of cells undergoing apoptosis and autophagy, Par-4 transiently transfected cells were treated with or without apoptotic stimulus in the presence or absence of an autophagy inhibitor. Cells were then fixed and permeabilized using BD Cytofix/Cytoperm solution (BD Biosciences) for 30 minutes at room temperature. After washing, cells were incubated with phycoerythrin-conjugated rabbit anti-LC3B antibody (Cell Signaling Technology) and fluorescein isothiocyanate-conjugated rabbit anti-active caspase 3 antibody (BD Biosciences) for 1 hour at $4^{\circ} \mathrm{C}$. Subsequently, $1 \times 10^{4}$ cells were harvested using an FACScan flow cytometer and further analyzed with CELLQuest version 3.0.1 and ModFitLT version 2.0 software.

\section{Staining}

Briefly, cells were labeled with $50 \mu \mathrm{mol} / \mathrm{L}$ monodansylcadaverine (MDC) reagent (Sigma-Aldrich) for $15 \mathrm{mi}-$ nutes. After washing with PBS, the fluorescence signal was immediately observed by fluorescence microscope with an excitation wavelength of $360 \mathrm{~nm}$ and an emission wavelength of $457 \mathrm{~nm}$. Autolysosomal distribution was quantified as the proportion of cells with predominant perinuclear localization of fluorescent vesicles.

\section{CHX Treatment}

For protein de novo synthesis, cells were pretreated with 40 $\mu \mathrm{mol} / \mathrm{L}$ cycloheximide (CHX) for 3 hours, then transfected with or without Par-4/pCMV6-XL6 plasmid in the absence of CHX (0 hours). At 24 hours after transfection, cell lysates were prepared and subjected to Western blot analysis using a primary antibody corresponding to Par- 4 , cleaved PARP, LC3B, or tubulin. The densities of the bands were measured using ImageJ software version 1.47 , and values were normalized to the densitometric values of tubulin in each sample. 
The fold change in protein amount was then calculated for the experimental sets compared with the vector control ( 0 hours).

\section{Co-Immunoprecipitation}

Cells were transfected with Par-4/pCMV6-XL6 or pGFP-LC3 plasmid, or cotransfected with both. At 48 hours after transfection, cells were harvested and lysed in lysis buffer. After preclearing with protein A-Sepharose beads (GE Healthcare Bio-Sciences AB, Uppsala, Sweden), cell lysates were incubated with antibody beads overnight at $4^{\circ} \mathrm{C}$. The immunocomplex was precipitated using protein $\mathrm{A}-$ Sepharose and washed three times in lysis buffer. The immunoprecipitates were resuspended in sample buffer and subjected to Western blot analysis. The density of the band was measured using ImageJ software version 1.47. For whole cell extracts, values were normalized to the densitometric values of actin in each sample. The fold change in protein amount was calculated for the experimental set compared with the vector control.

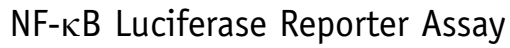

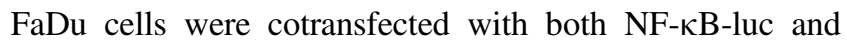
pRL-TK vector (Promega, Madison, WI) plus either Par-4/ pCMV6-XL6 or Par-4-GFP expression plasmid. At 48 hours after transfection, the luciferase activity of each sample was measured using the Dual Luciferase Reporter Assay System (Promega), according to the manufacturer's instructions, and calculated by dividing the value of luciferase activity/the value of Renilla luciferase activity. The relative luciferase activity was represented as the fold of activation via the experimental set over the NF- $\mathrm{BB}-$ dependent luciferase reporter alone.

\section{Phospho-Kinase Array Analysis}

Briefly, FaDu cells were transfected with or without Par-4/ pCMV6-XL6 plasmid, and at 48 hours after transfection, diluent cell lysates were prepared and subjected to a protein kinase array using a Proteome Profiler Human PhosphoKinase Array Kit (R\&D Systems, Minneapolis, MN), according to the manufacturer's instructions. The array membranes were washed, followed by incubation with a mixture of biotinylated detection antibodies and streptavidinhorseradish peroxidase antibodies. Phospho-kinase signals were then detected using a chemiluminescent detection reagent, and the density of each spot was further measured using ImageJ software version 1.47. The fold change of each phosphorylated protein was calculated as the value of the experimental set compared with the value of the vector control.

\section{Statistical Analysis}

Statistical differences were analyzed using the paired $t$-test and were considered to be significant at $P<0.05$.

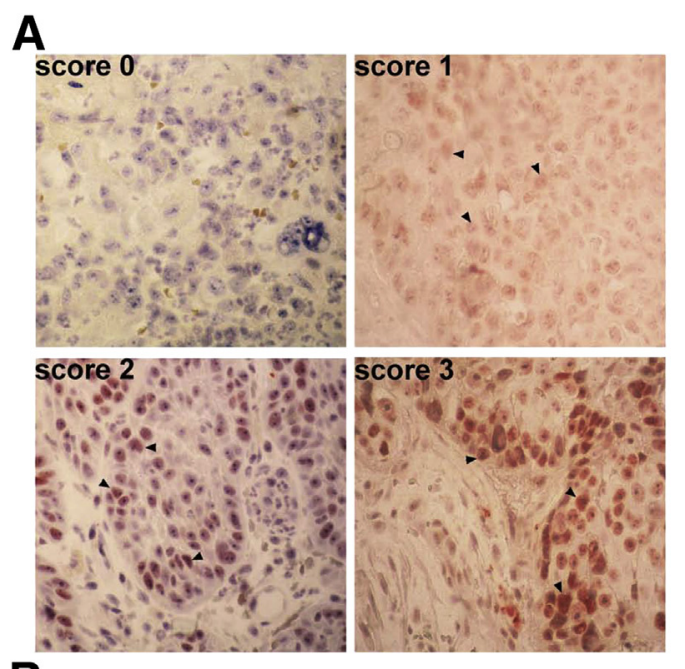

B

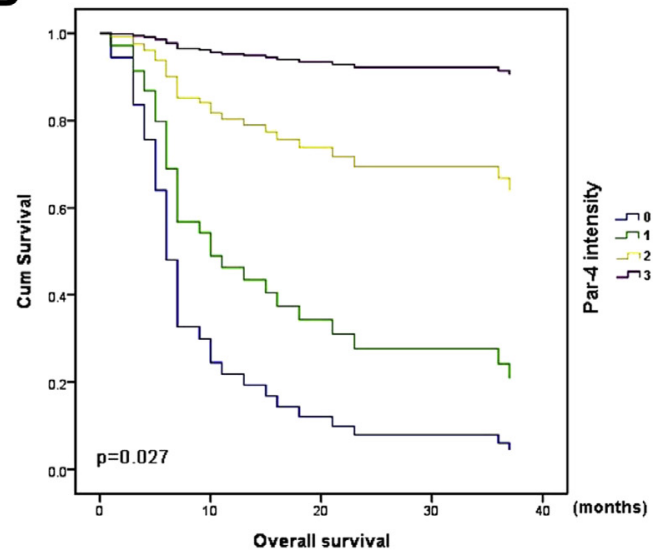

Figure 1 The intensity of Par-4 significantly correlates with the overall survival of patients with HPC undergoing radiotherapy alone or CCRT. Fortyfive patients who underwent radiotherapy or CCRT treatment were included for analysis. A: Representative results for Par-4 showed nuclear-positive staining (arrowheads) by immunohistochemistry. ${ }^{11}$ Original magnification, $\times 400$. The overall (average) protein intensity was evaluated by pathologists, according to the percentage of signal accumulation in the nuclei, and scored as follows: 0 , no staining signal; 1 , weak $(<10 \%) ; 2$, moderate $(10 \%$ to $50 \%)$; 3 , strong $(>50 \%)$. B: The survival function of Par- 4 intensity and the $P$ value were calculated after adjusting for the American Joint Committee on Cancer stage and the expression percentage of Par- $4 .{ }^{11}$ Cum, cumulative.

\section{Results}

The Intensity of Par-4 Is Significantly Correlated with Overall Survival of Patients with HPC Undergoing Radiotherapy Alone or CCRT

We previously showed expression of Par-4 in half of tested HPC specimens. ${ }^{11}$ In the current study, we assessed the significance of Par-4 in HPC. Clinical information from 93 patients with HPC, including 47 Par-4-negative and 46 Par4-positive cases, was collected to examine the relationships with expression percentage and staining intensity of Par-4. For all patients, Par-4 was unrelated to age, sex, TNM classification, or clinical stage (data not shown). We further divided these patients into two sets according to treatment. In 48 patients undergoing surgery, there was no correlation between 
A
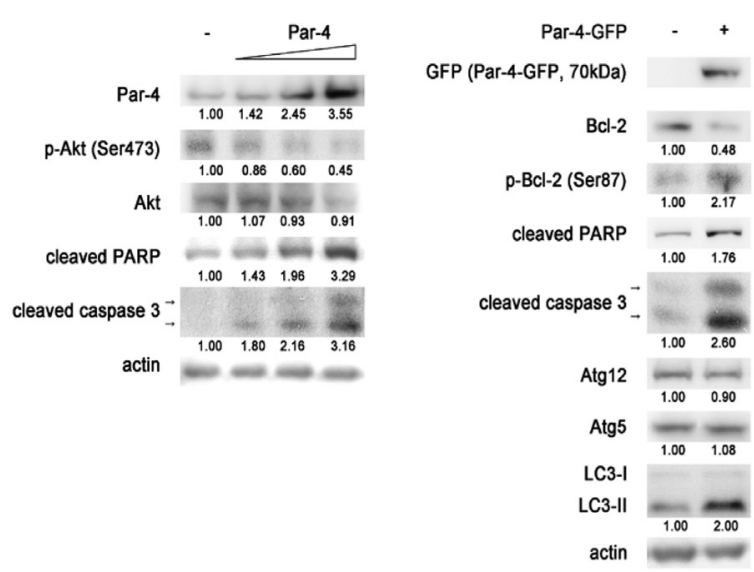

B
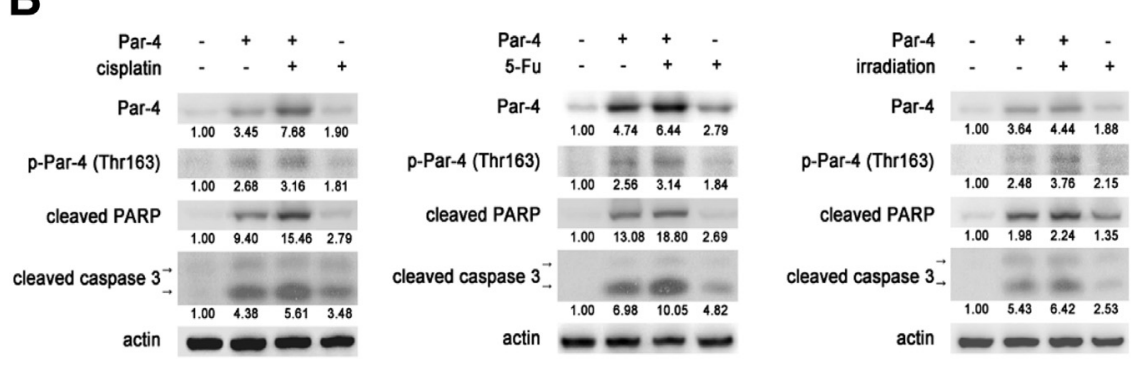

C

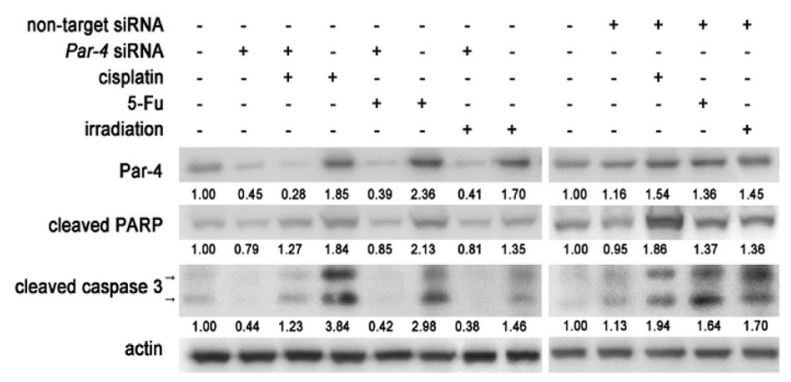

Figure 2 Overexpression of Par-4 results in HPC cell apoptosis and sensitizes cells toward the apoptotic agent. A: Cells were transiently transfected with $0.5,1$, and $2 \mu \mathrm{g}$ Par-4 expression plasmid or $1.5 \mu \mathrm{g}$ Par-4-GFP plasmid. At 48 hours after transfection, cell lysates were harvested and subjected to Western blot analysis using primary antibodies against the indicated proteins. In addition, transfection with pcDNA3 (left panel) or pEGFP-N1 (right panel) served as an empty control. B: For the sensitization assay, FaDu cells were transiently transfected with $2 \mu \mathrm{g}$ Par- 4 expression plasmid, and at 24 hours after transfection, cells were treated with or without a sublethal dose $\left(<\mathrm{LD}_{50}\right)$ of $1 \mu \mathrm{g} / \mathrm{mL}$ cisplatin or $1.5 \mu \mathrm{mol} / \mathrm{L} 5-\mathrm{Fu}$ for an additional 48 hours. On the other hand, after transfection for 48 hours, cells were irradiated with or without 6 Gy X-ray for 24 hours. Cell lysates were harvested and subjected to Western blot analysis using primary antibodies against the indicated proteins. In addition, transfection with pcDNA3 served as an empty control. C: For the knockdown assay, FaDu cells were transfected with 150 pmol siRNA targeting Par-4 in the presence of $5 \mu \mathrm{g} / \mathrm{mL}$ cisplatin, $2 \mu \mathrm{mol} / \mathrm{L} 5$-Fu, or 6 Gy X-ray irradiation. Cell lysates were then collected and subjected to Western blot analysis for Par-4, cleaved PARP, cleaved caspase 3 , or actin. All Western blot analysis data shown are representative of three independent experiments. The protein expression fold change was calculated as described in Materials and Methods.
Par-4 and treatment outcome (data not shown). However, in contrast to 15 Par-4-negative cases, in the radiotherapy alone or concurrent chemoradiotherapy (CCRT) set, the intensity of Par-4 in 30 Par-4-positive patients revealed a statistically significant and positive correlation with overall survival after adjustment for American Joint Committee on Cancer stage and the expression percentage of Par-4 (Figure 1). Moreover, by grouping analysis, it was also better than separate analysis for each mode of treatment as the result of no statistical significance in CCRT $(P=0.060, N=34)$ or few case number in radiotherapy ( $P=0.003, N=11$ ) (data not shown). Consequently, this result apparently suggests a prognostic role of Par-4 in patients with HPC who undergo radiotherapy alone or in conjunction with chemoradiation for treatment.

\section{Elevated Expression of Par-4 Directly Induces HPC Cell Apoptosis and Enhances the Cell Sensitivity toward Apoptotic Stimuli}

Our previous studies suggested an apoptotic threshold of Par4 , which is associated with the incitement of apoptosis. ${ }^{11,42,45}$
To expound on the clinical role of Par-4 in HPC (Figure 1), we examined whether augmentative expression of Par-4 confers irradiation- or chemotherapeutic agent-provoked apoptosis. In HPC cells, an increase in cleaved caspase 3 and cleaved PARP was obviously displayed on overexpression of Par-4 or GFP-tagged Par-4 (Figure 2, A and B). In addition, the expression levels of phosphorylated Akt (Ser473), a Par-4 antagonist, ${ }^{15}$ and a Par-4 downstream target, Bcl-2, ${ }^{20}$ were also decreased (Figure 2A). Moreover, in contrast to moderate induction of apoptosis by cisplatin, fluorouracil (5-Fu), or X-ray irradiation lower than the lethal dose $\left(<\mathrm{LD}_{50}\right)$ concentration, additional Par-4 conduction remarkably enhanced the sensitivity of HPC cells, leading to more caspase 3 and PARP cleavage, as well as cell death (Figures $2 \mathrm{~B}$ and 3A). Although expression of endogenous Par-4 was partly induced by an apoptotic agent, apoptotic agent-incited apoptosis and cell death was lower than that in combination with exogenous Par-4 overexpression (Figures 2B and $3 \mathrm{~A}$ ). Thus, these results indicated that Par-4 itself and the expression amount (intensity) correlated with pro-apoptosis activity. Accordingly, by using siRNA targeting Par-4, HPC 


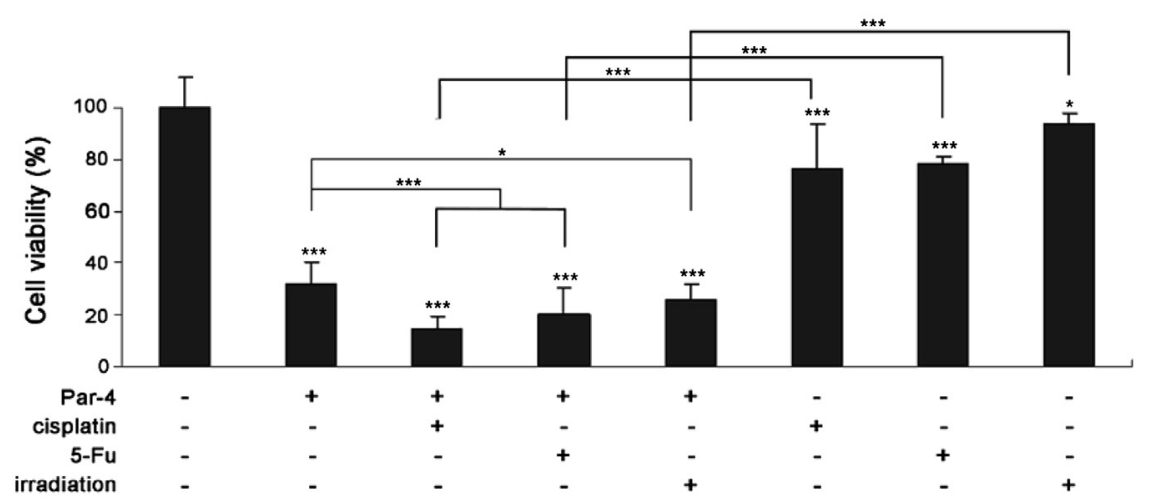

B

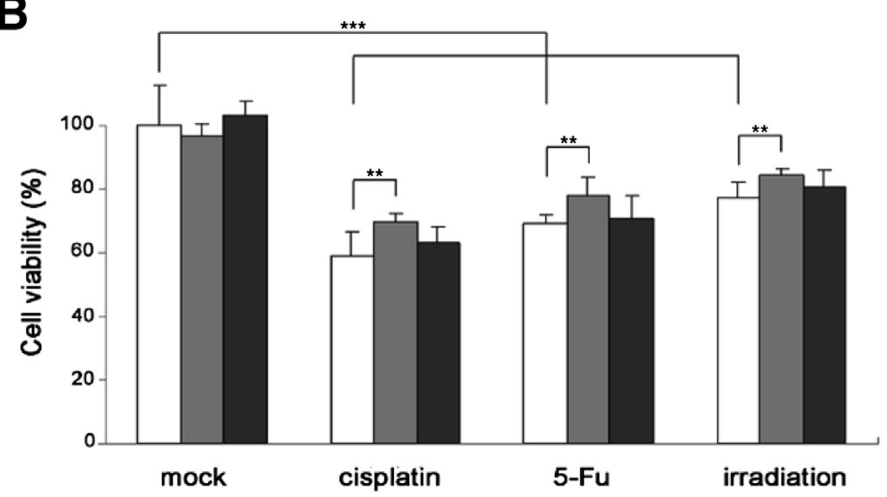

cells apparently showed resistance to apoptosis and attenuated cell death when encountering a higher dosage $\left(>\mathrm{LD}_{50}\right)$ of cisplatin, 5-Fu, or X-ray irradiation (Figures 2C and 3B). In conclusion, these data suggest that an increase of Par-4 sufficiently induces apoptosis and contributes to cell death by apoptotic irritants.

\section{Overexpression of Par-4 Promotes Autophagic Flux in HPC Cells}

Apart from the Par-4 pro-apoptosis activity, we also found up-regulation of autophagy by Par-4 stimulation. Via TEM examination, HPC cells manifested membranous autophagic vacuoles through exogenous Par-4 delivery (Figure 4A). In the autophagosome synthesis, in particular, the cytoplasmic localization of LC3-I changes to the lipidated form (LC3-II) through conjugation with phosphatidylethanolamine and is recruited to the autophagosomal membrane. Therefore, monitoring the intracellular localization of LC3 or conversion from LC3-I to LC3-II is widely used as a marker for autophagosome measurement. ${ }^{33,43}$ Because of the LC3 property, to validate autophagy activation by Par-4, we introduced GFP-LC3 reporter to HPC cells; on the other hand, we also established a stably expressing GFP-LC3 cell line for analysis. Compared with the diffusion pattern of GFP-LC3 in the vector control, on overexpression of Par-4, the number of cytoplasmic GFP-LC3 puncta was distinctly increased (Figure 4B). Because autophagy is a dynamic 口untransfected

$\square$ Par-4 siRNA

non-target siRNA
Figure 3 Overexpression of Par-4 confines HPC cell viability. A and B: FaDu cells were treated under the same experimental conditions as described in Figure 2, B and C, respectively. In addition, in $\mathbf{A}$, all experiments were performed in autophagy inhibitor-free (3-MA) circumstances. Cells were then subjected to a cell viability assay. The percentage of cell viability was calculated as described in Materials and Methods and is shown as the means \pm SD of three independent experiments. ${ }^{*} P<0.05,{ }^{* *} P<0.01$, and ${ }^{*} * P<0.001$. process, after maturation, autophagosomes fuse with lysosomes (autolysosomes), resulting in autophagosome content and LC3-II degradation. ${ }^{33,35}$ Thus, accumulation of GFPLC3 puncta is possible from a substantial increase in autophagic flux or impeded autolysosome formation. To clarify this issue, Par-4 and GFP-LC3-cotransfected HPC cells were treated with a phosphatidylinositol 3-kinase inhibitor, 3-methyladenine (3-MA), or bafilomycin A1 (BafA 1), which prevents the late phase of autophagy by inhibiting fusion between autophagosomes and lysosomes. In contrast to untreated cells, fluorescence images and quantification of GFP-LC3 dots revealed that overexpression of Par-4 caused an autophagosome increase (Figure 4, B and C), but also significantly enhanced autophagy processing because of a reduced number of fluorescent punctate cells by 3-MA inhibition and, reversely, augmentation after BafA 1 treatment (Figure 4C).

Fluorescence of GFP quenches at the low $\mathrm{pH}$ inside lysosomes, but GFP is still stable; accordingly, free GFP can be generated by partial degradation of GFP-LC3 in autolysosomes. ${ }^{46}$ In agreement with these characteristics, in GFPLC3-expressing HPC cells without 3-MA or BafA 1 treatment, additional Par-4 delivery apparently resulted in a fluorescence intensity decrease relative to the control, yet this was reversed in the presence of autophagy inhibitors (Figure 5A). Moreover, in contrast to the vector control or 3-MA inhibition, accrual conversion from LC3-I to LC3-II (Figure 2A and Supplemental Figure S1), along with a 
A

Par-4
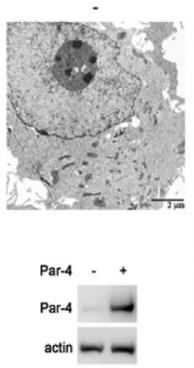

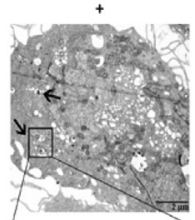

B
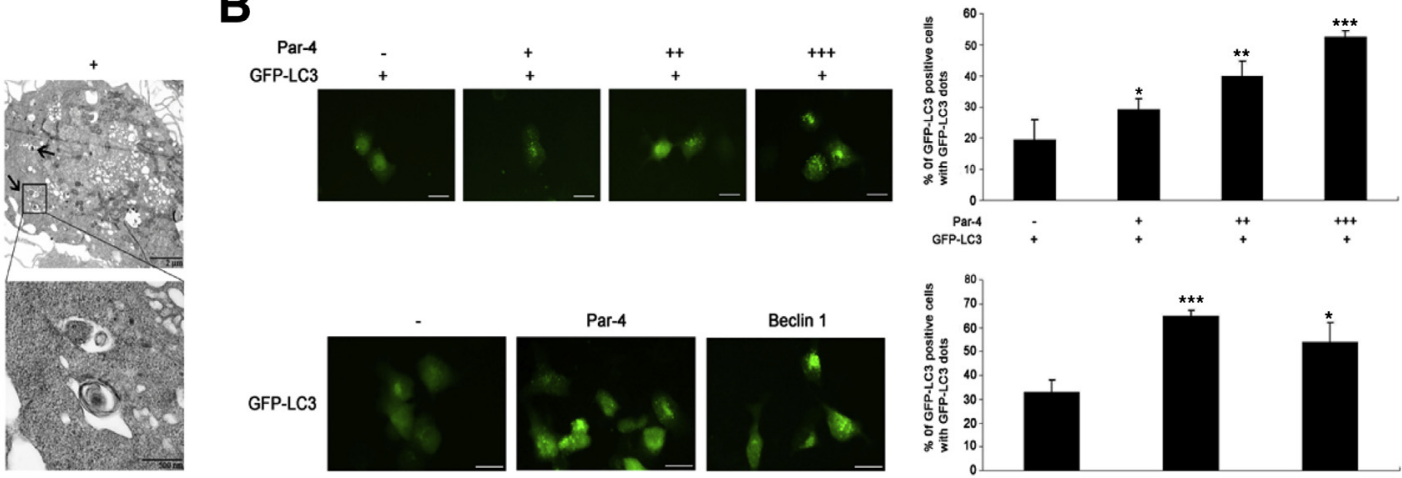
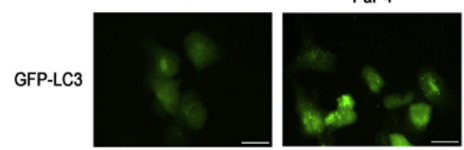

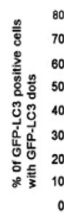

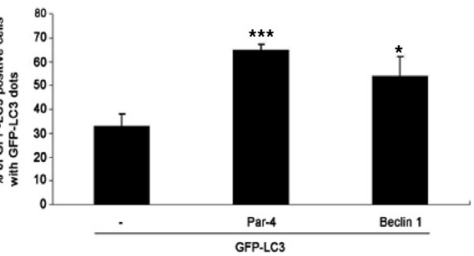

C
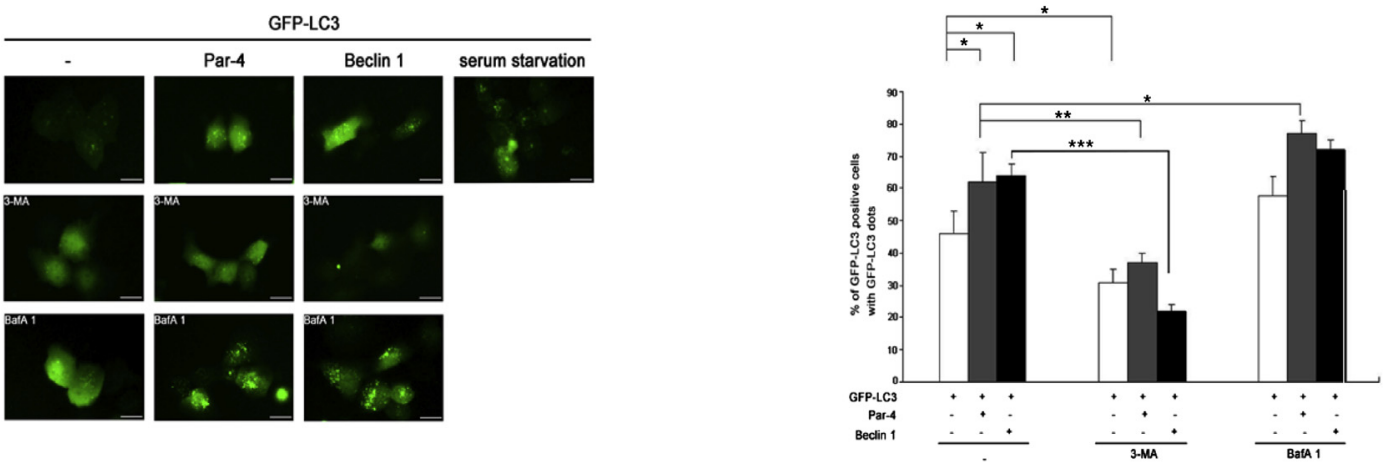

Figure 4 Elevated expression of Par-4 facilitates autophagy in HPC cells. A: Representative TEM microphotograph of FaDu cells with Par-4 transfection or pcDNA3 empty control. The arrows indicate autophagic vacuoles. In addition, cell lysates were harvested and subjected to Western blot analysis for Par-4 or actin. B: GFP-LC3 puncta in FaDu cells with GFP-LC3 and an ascending concentration (0.5, 1, or $1.5 \mu \mathrm{g})$ of Par-4 cotransfection, or FaDu cells stably expressing GFP-LC3 with Par-4 or Beclin 1 transfection, were examined by fluorescence microscope. In addition, transfection with pcDNA3 served as an empty control. C: Representative fluorescence images of GFP-LC3 puncta in FaDu cells with GFP-LC3 transfection alone, or plus either Par-4 or Beclin 1 cotransfection in the presence or absence of $5 \mathrm{mmol} / \mathrm{L} 3-\mathrm{MA}$ or $5 \mathrm{nmol} / \mathrm{L}$ BafA 1 . Serum starvation and pcDNA3 transfection were used as an autophagy inducer and empty control, respectively. The percentage of GFP-LC3-positive cells with GFP-LC3 dots was calculated as described in Materials and Methods and is shown as the means \pm SD of three independent experiments. ${ }^{*} P<0.05,{ }^{*} P<0.01$, and ${ }^{* *} P<0.001$.

reduced GFP-LC3 amount, increased free GFP fragments (Figure 6B) and predominant perinuclear autolysosomes dots (Figure 5B), ${ }^{47}$ which further underlined the Par-4 proautophagic flux activity. Taken together, these results reveal that augmented expression of Par-4 evidently activates the autophagy machine in HPC cells.

\section{Apoptosis and Autophagy Are Simultaneously Activated by Par-4 by Acting on Multiple Regulators}

Par-4-activated autophagy reduced cell viability, but this was partially mitigated in the presence of an autophagy inhibitor (Figure 3A and Supplemental Figure S2). To determine the relationship between apoptosis and autophagy by Par-4 induction, we examined the occurrence times of apoptosis and autophagy during Par-4 overexpression. HPC cells were pretreated with CHX to synchronize Par-4 translation, and after removal of CHX, apoptosis and autophagy were analyzed. Relative to exogenous Par-4 introduction at the beginning (0 hours), the cleaved PARP and LC3-II amounts simultaneously increased under overexpression of
Par-4 for 24 hours (Figure 7A). This result implied that Par-4 facilitated apoptosis and autophagy at the same time. To demonstrate this possibility, we further assessed these two biological phenomena via flow cytometry. Relative to the untreated vector control, a lower percentage of cells with apoptosis and/or autophagy under cisplatin, 5-Fu, or X-ray irradiation treatment was displayed. On additional Par-4 introduction, the percentages of the apoptosis or autophagy populations were obviously increased, but there was a greater distribution of cells in autophagy. Intriguingly, $15 \%$ to $30 \%$ of cells presented concomitant activation of these cellular processes (Figure 7B and Supplemental Figure S3A). Eventually, cell viability was reduced by Par-4-induced apoptosis and autophagy (Figure 3A and Supplemental Figure S2). Conversely, the percentage of cells entering apoptosis and/or autophagy was decreased in the presence of an autophagy inhibitor, and cells revealed moderate recovery of cell viability (Supplemental Figures S2B and S3B). Particularly, in contrast to lacking an inhibitor, the elevated percentage of apoptotic cells under cisplatin or 5-Fu treatment or in combination with overexpression of Par-4 was manifested after autophagy inhibitor addition (Supplemental Figure S3B); 

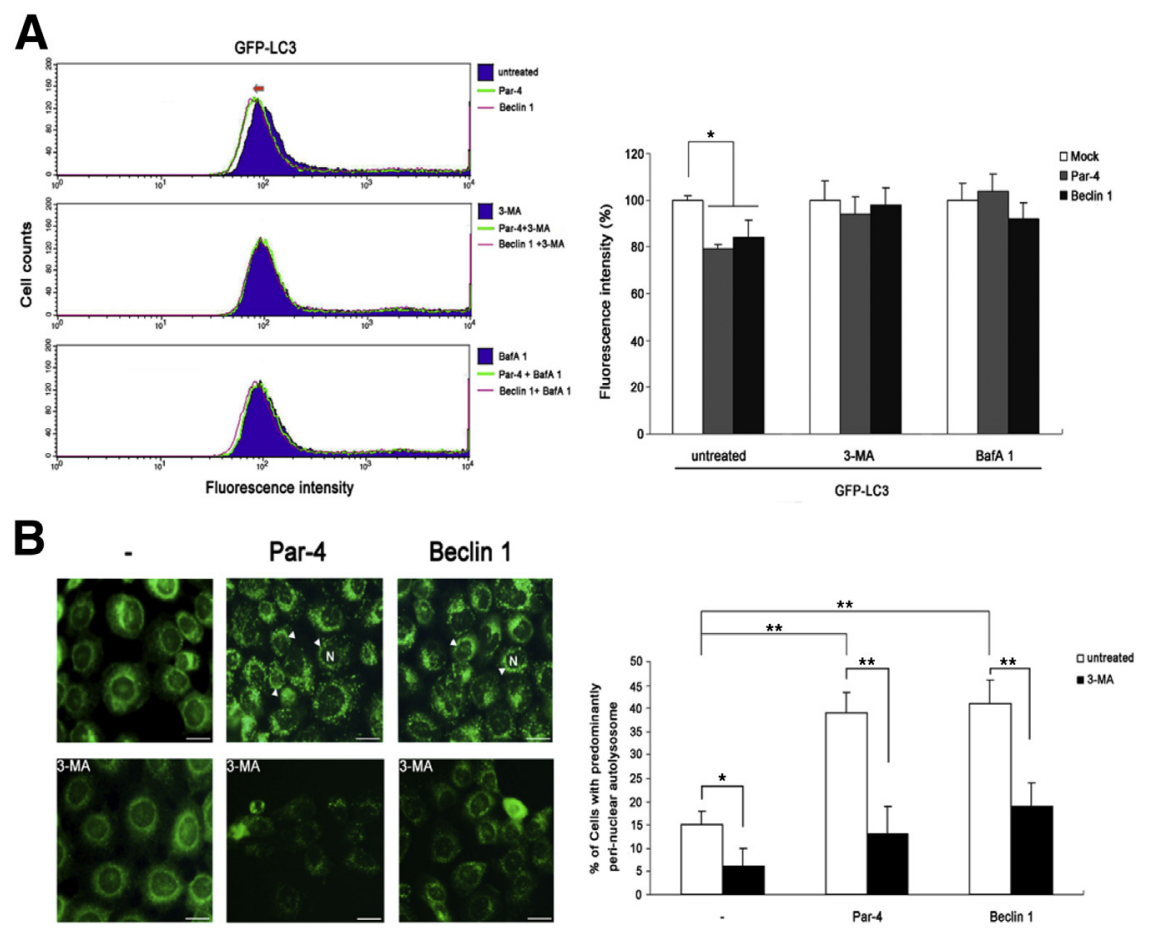

Figure 5 Overexpressing Par-4 enhances autophagic flux in HPC cells. A: For quantification of the turnover of GFP-LC3, FaDu cells were transiently transfected with GFP-LC3 plasmid alone or cotransfected with either Par-4 or Beclin 1 expression plasmid in the presence or absence of 5 $\mathrm{mmol} / \mathrm{L} 3-M A$ or $5 \mathrm{nmol} / \mathrm{L}$ BafA 1 . Samples were then prepared, and the intensity of GFP-LC3 was measured using flow cytometry. Reduced GFP-LC3 fluorescence is indicated (arrow) in the representative histogram. The relative fluorescence intensity of each sample was calculated as described in Materials and Methods and is shown as the means \pm SD of three independent experiments. B: FaDu cells were transiently transfected with Par-4 or Beclin 1 expression plasmid in the presence or absence of $5 \mathrm{mmol} / \mathrm{L} 3-\mathrm{MA}$. At 48 hours after transfection, autolysosomes were labeled with an autolysosome tracer, MDC reagent, and observed by fluorescence microscope. Transfection with pcDNA3 was used as an empty control. The perinuclear localization of autolysosomes is indicated (arrowheads), and the distribution percentage was quantified as described in Materials and Methods, and is shown as the means \pm SD of three independent experiments. ${ }^{*} P<0.05,{ }^{* *} P<$ 0.01 . N, nucleus. however, cell viability was still increased, with the exception of apoptotic agent treatment alone (Supplemental Figure S2B). Of interest, Par-4-induced cell death was not apparently changed in the presence of a pan-caspase inhibitor (data not shown). Considering the influence of apoptosis and autophagy in HPC cells, collectively, these data suggest profound effects of Par-4-induced autophagy and apoptosis on cell death. In addition, relative to apoptosis, autophagy activation by Par-4 may play a dominant role to influence cell fate (Supplemental Figure S4).

Next, we sought to identify common regulators that participate in the activation of apoptosis and autophagy by Par-4. Although the amounts of core components of autophagy involved in apoptosis, such as $\operatorname{Atg} 12$, Atg5, mammalian target of rapamycin, or Beclin 1, were constant regardless of the elevated expression of Par-4, the expression levels of Bcl-2 and activated Akt were decreased on overexpression of Par-4 (Figure 2A and data not shown). ${ }^{35,37,38,40}$ Of interest, phosphorylation of Bcl-2 at residue Ser87, which mediates autophagy stimulation, ${ }^{48}$ was increased owing to exogenous Par-4 introduction (Figure 2A). Accumulating evidence indicates that $\mathrm{p} 62$ (alias sequestosome-1) acts as a signaling hub to mediate autophagy via interacting with ubiquinated cargo and LC $3{ }^{41}$ In addition, it has also been shown that p62 forms a ternary complex with PKC $\zeta$ and Par4 to antagonize Par-4-mediated PKC $\zeta$ inhibition and protect cells from apoptosis through NF- $\kappa \mathrm{B}$ re-activation. ${ }^{49,50}$ To assess whether p62 is involved in Par-4-induced apoptosis and autophagy, overexpressing Par-4 cells were immunostained with a primary antibody against p62 and subjected to flow cytometry. Similar to the altered expression of p62 within autophagy, ${ }^{51}$ the fluorescence intensity of p62 was obviously elevated at 24 hours relative to the mock control, but recovered at 48 hours after transfection (Figure 6A). Consistently, immunoprecipitation displayed that elimination of $\mathrm{p} 62$ by Par- 4 further disrupted the interaction between p62 and LC3 or PKC $\zeta$, and led to inhibition of NF- $\kappa \mathrm{B}$ activity (Figure 6, B and C). Thus, these results indicate that the behavior of p62 is involved in Par4-activated apoptosis and autophagy. In addition, we also determined the regulatory pathways of apoptosis and autophagy. By overexpressing Par-4, the protein amounts of various phosphorylated kinases involved in apoptosis and autophagy were altered in contrast to the vector control (Figure 8 and Supplemental Table S1). Through affecting multiple molecules, collectively, these data suggest that simultaneous activation of apoptosis and autophagy by Par-4 contributes to cell death, which accounts for the prognostic role of Par-4 in HPC (Figure 1).

\section{Discussion}

Our previous studies revealed a dramatic discrepancy in the expression percentage of Par-4 between nasopharyngeal carcinoma and HPC. ${ }^{11}$ In the present study, statistical analysis further indicated a significant survival function of Par-4 intensity in patients with HPC undergoing radiotherapy or chemoradiotherapy (Figure 1). Accordingly, these results suggested that Par-4 plays a prognostic role in HPC and serves as a marker to distinguish between different head and neck cancers. Mechanistically, Par-4 augmentation by exogenous Par-4 delivery efficiently resulted in apoptosis. In addition, additional Par-4 introduction also obviously sensitized HPC cells toward apoptotic stimuli. 

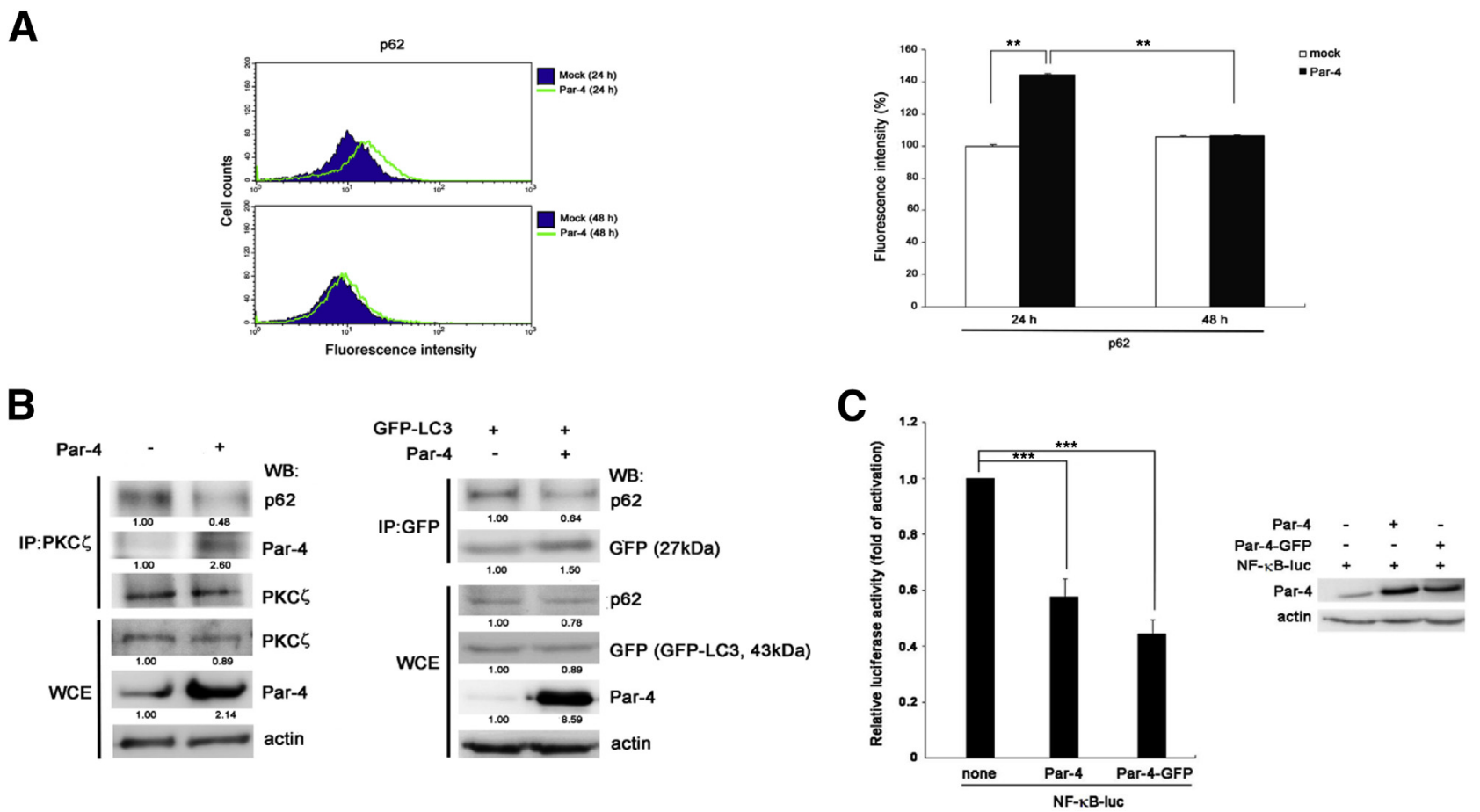

Figure 6 p62 Is involved in coregulation of apoptosis and autophagy by Par-4. A: For quantification of p62, FaDu cells were transiently transfected with or without Par-4 expression plasmid for 24 or 48 hours. Cells were then immunostained with primary antibody against p62, followed by incubation with fluorochrome-conjugated secondary antibody. The fluorescence intensity was measured using flow cytometry. The relative fluorescence intensity of each sample was calculated as described in Materials and Methods and is shown as the means \pm SD of three independent experiments. B: Cell lysates from the indicated transfectants were subjected to immunoprecipitation with PKC $\zeta$ or GFP antibody. The immunoprecipitates and inputs (WCE) were subjected to

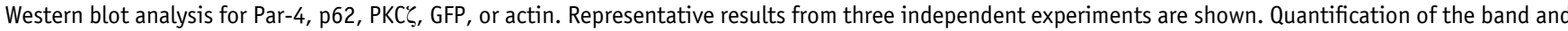
fold change of protein amount were calculated as described in Materials and Methods. pcDNA3 transfection was used as the empty control. C: FaDu cells were cotransfected with both NF-KB-luc and pRL-TK vector, plus either Par-4 or Par-4-GFP plasmid. After transfection for 48 hours, the luciferase activity of each sample was measured and the relative luciferase activity was calculated as described in Materials and Methods, and is shown as the means \pm SD of three independent experiments. In addition, exogenous Par-4 was also displayed using Western blot analysis. All Western blot analysis data shown are representative of three independent experiments. ${ }^{* *} P<0.01,{ }^{* * *} P<0.001$.

Conversely, partial apoptosis was observed as the result of a lower increase of endogenous Par-4 by a lower concentration $\left(<\mathrm{LD}_{50}\right)$ of apoptotic agent alone (Figures $2 \mathrm{~B}$ and $3 \mathrm{~A}$ ). In light of the apoptotic threshold of Par-4, as described previously, ${ }^{11,42,45}$ these data implied that the intensity (amount) of Par- 4 could be used as a valuable marker to evaluate the therapeutic efficacy in patients with HPC before radiotherapy alone or in combination with chemotherapy. Along with Par-4 pro-apoptosis activity, we also observed a decrease in the amount of $\mathrm{Bcl}-2$, which could be correlated with transcriptional inhibition via Par-4 and WT1 interaction or Par-4-induced abnormal miRNA expression, leading to translation attenuation. ${ }^{20,62}$ In addition, negative regulation of Akt activity by the Par-4/PKC $\zeta$ complex could account for the reduction of phosphorylated Akt (Ser473) on Par-4 overexpression. ${ }^{29}$

Of interest, we discovered autophagy enhancement by Par-4, in addition to apoptosis incitation. Similar to starvation-induced alteration of lysosome position, ${ }^{63}$ perinuclear autolysosome accumulation under overexpression of Par-4 (Figure 5B) could be ascribed to intracellular lysosomes clustering to the microtubule organizing center, eventually fusing with autophagosomes. In the autophagy machine, p62 brings ubiquitinated protein aggregates to autophagosomes via interaction with LC3, followed by degradation of cargo and p62 in autolysosomes. ${ }^{35}$ In concert with the perinuclear clustering of autolysosomes, p62 speckles around the nucleus were observed in response to exogenous Par-4 conduction (data not shown). Via protein de novo synthesis analysis and flow cytometry, we showed that autophagy was activated after Par-4 overexpression for 24 hours; meanwhile, the expression level of p62 was elevated and further declined at 48 hours (Figures $6 \mathrm{~A}$ and $7 \mathrm{~A}$ ). These results consequently corroborated Par-4-induced dynamic alteration of the autophagy process. Consistently, the changed expression of p62 has also been reported in autophagycompetent/apoptosis-defective cells under metabolic stress. ${ }^{51}$ However, p62 is a target for caspase 8 cleavage ${ }^{40,41}$; therefore, whether Par-4-activated apoptosis also contributes to degradation of p62 should be further clarified.

Intriguingly, our results indicated concomitant stimulation of apoptosis and autophagy by Par-4 consistently; the cell populations with apoptosis and autophagy were also increased on overexpression of Par-4 (Figure 7). Relative to apoptosis induction, our data further suggested a dominant role of Par4-activated autophagy in cell viability (Figures $3 \mathrm{~A}$ and $7 \mathrm{~B}$ 
A

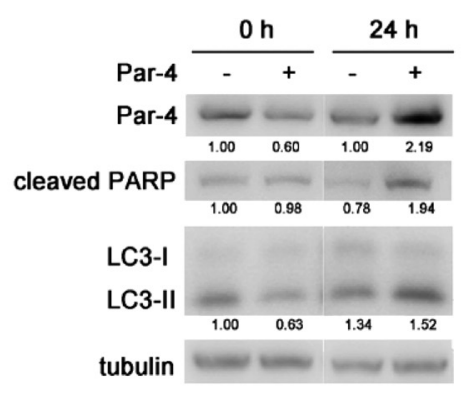

B

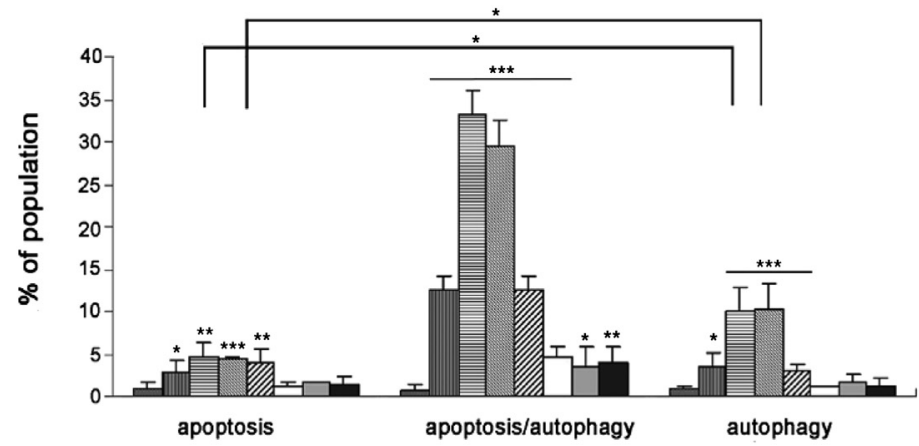

$\square-$

प Par-4

目 Par-4 + cisplatin

ㅁ Par-4 + 5-Fu

Q Par-4 + irradiation

$\square$ cisplatin

$\square$ 5-Fu

口 irradiation

Figure 7 Concomitant activation of apoptosis and autophagy by overexpression of Par-4. A: FaDu cells were pretreated with 40 umol/L CHX; cells were then transfected with Par-4 expression plasmid in the absence of CHX (0 hours). At 24 hours after transfection, cell lysates were prepared and subjected to Western blot analysis for Par-4, cleaved PARP, LC3B, or tubulin. In addition, transfection with pcDNA3 served as an empty control. Representative results from three independent experiments are shown. The protein expression fold change was calculated as described in Materials and Methods. B: For measurement of the cell populations with apoptosis and/or autophagy, Par-4 or pcDNA3 vector-transfected cells were treated with or without $1 \mu \mathrm{g} / \mathrm{mL}$ cisplatin, $1.5 \mu \mathrm{mol} / \mathrm{L} 5$-Fu, or 6 Gy X-ray. In addition, all experiments were performed under autophagy inhibitor-free (-3-MA) conditions. Samples were then prepared for flow cytometry as described in Materials and Methods. The percentages of the cell population entering apoptosis and/or autophagy of each sample are shown as the means \pm SD of three independent experiments. ${ }^{*} P<0.05,{ }^{*} P<0.01$, and ${ }^{*} * * P<0.001$.

and Supplemental Figures S2B, S3B, and S4). Particularly, in autophagy-defective conditions (3-MA addition), cell death was conversely enhanced under chemotherapeutic agent treatment alone (Supplemental Figure S2B), which could be due to chemical interaction. In addition, in this case, whether autophagy served as a cell survival promoter or contributor in cell death should be further investigated. Although autophagic cell death or cell death with autophagy remains uncertain, ${ }^{64}$ emerging evidence has indicated that autophagy can contribute to apoptosis-independent cell death and suggests a tumor-suppressive activity. ${ }^{37,65,66}$ Therefore, in contrast to basal autophagy in HPC cells, excessive activation of autophagy by Par- 4 could promote cell collapse. There are many common components and switching points, including calpainor caspase-mediated Atgs cleavage, as well as Bcl-2 family and Beclin 1 interaction, which have been identified to establish a connection between apoptosis and autophagy. ${ }^{38-41,67-71}$ In
HPC cells, we did not observe cleaved forms of Atg5 and Beclin 1 under Par-4-induced apoptotic conditions (data not shown). However, we showed an increased expression of phosphorylated Bcl-2 at residue Ser87 in response to Par-4 increase (Figure 2A), which is concordant with autophagy stimulation by c-Jun N-terminal kinase $1-$ mediated Bcl-2 phosphorylation at residues Thr69, Ser70, and Ser87. ${ }^{48}$ Moreover, the activated phosphorylation of several kinases involved in apoptosis and autophagy was also influenced by Par-4, including c-Jun N-terminal kinase 1 (Figure 8 and Supplemental Table S1). Together with down-regulation of Bcl-2 and activated Akt by Par-4 (Figure 2), our data indicated a complex interplay and suggested that apoptosis and autophagy were not mutually exclusive under Par-4 induction circumstances. However, whether Par-4 can modulate modifications of autophagy core components, dissociate the Bcl-2/Beclin 1 complex via enhancing $\mathrm{BH} 3$-only pro-apoptotic protein

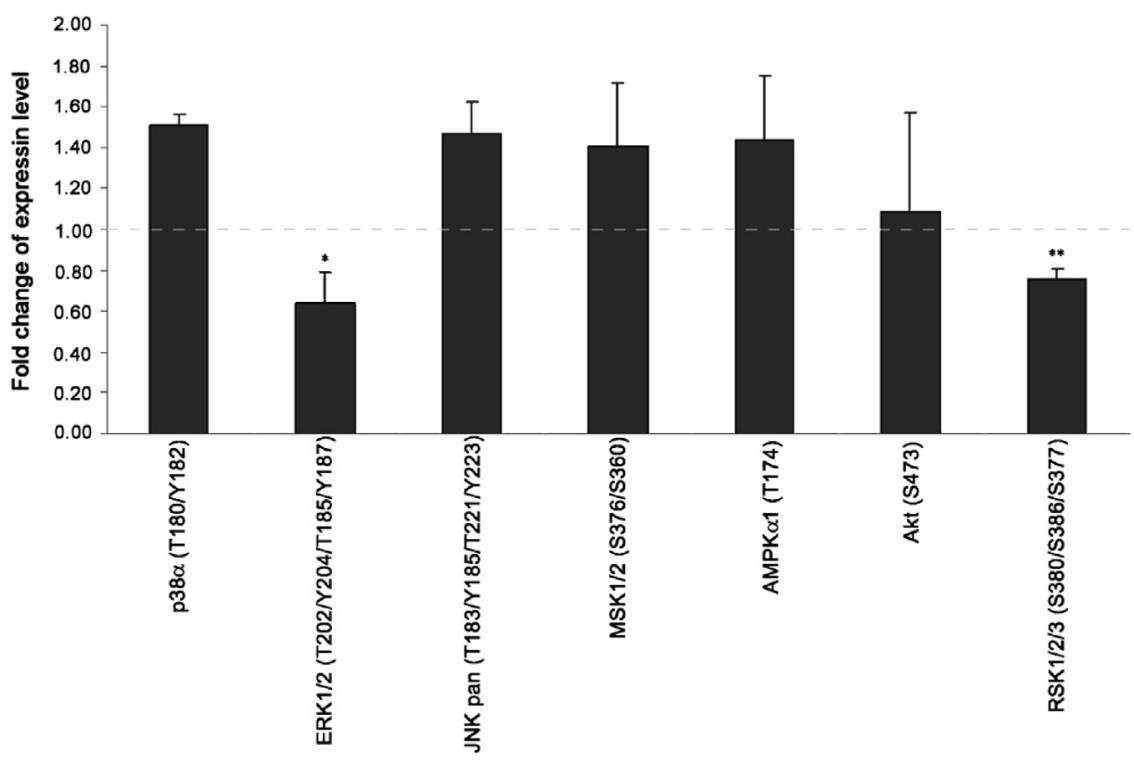

Figure 8 Overexpression of Par-4 leads to alteration of the amounts of various phosphorylated kinases. FaDu cells were transiently transfected with Par-4 expression plasmid, and at 48 hours after transfection, diluent cell lysates were prepared and subjected to protein kinase array analysis. The densities of the signals of the phospho-kinases were measured and the fold change of each phosphorylated protein was calculated as described in Materials and Methods and is shown as the means \pm SD of three independent experiments. ${ }^{*} P<0.05,{ }^{*} * P<0.01$. 
binding affinity, direct Beclin1 escape from microtubule association, or activate the autophagy-dependent immune response to regulate apoptosis and autophagy at the same time is worthy of investigation. ${ }^{71-74}$

Another important connector participating in Par-4induced apoptosis and autophagy is p62. Functionally, p62 can directly interact with multiple proteins, including mitogen-activated protein kinase kinase, extracellular signal-regulated kinase, receptor-interacting protein, tumor necrosis factor receptor-associated factor, atypical PKC, ubiquitin, and LC3, through its respective domain; thus, p62 influences NF- $\kappa \mathrm{B}$ activation, cell growth, apoptosis, and autophagy. ${ }^{41}$ In addition, degradation of caspase 8 within autophagy and cleavage of p62 by caspase 8 during apoptosis also establish a complicated connection between apoptosis and autophagy. ${ }^{40,41,67}$ Evidence has revealed that accumulation of p62 in autophagy-defective tumor cells can induce reactive oxygen species and genome damage and alter NF- $\mathrm{KB}$ signaling, thereby enhancing tumorigenesis. ${ }^{51}$ Remarkably, our data indicated that Par-4-mediated elimination of p62 interfered with p62 binding to PKC $\zeta$ and $\mathrm{LC} 3$, respectively, and led to repression of NF- $\mathrm{BB}$ transcriptional activity (Figure 6), consistent with the inhibition of NF- $\kappa \mathrm{B}$ via limiting PKC $\zeta$ activity by Par- $4,{ }^{49,50}$ and confined tumor cell survival through down-regulation of tumor-prone protein p62 within apoptosis and autophagy.

In summary, to our knowledge, this is the first study to indicate novel pro-apoptosis and autophagy activity of Par-4 to support a prognostic role in HPC survival. Furthermore, our data suggest that it is of benefit to develop Par-4 as a marker for therapeutic strategies or efficacy evaluation. In addition, inducing Par-4 expression in combination with radiotherapy or chemoradiotherapy could be a desirable management strategy for cancer therapy.

\section{Acknowledgments}

We thank Dr. Chia-Chin Liu and Li-Ting Lin for technical assistance in the TEM and X-ray irradiation experiments, respectively, and Dr. Cheng-Yung Lee for clinical statistical analysis.

\section{Supplemental Data}

Supplemental material for this article can be found at http://dx.doi.org/10.1016/j.ajpath.2013.10.012.

\section{References}

1. Mineta H, Miura K, Suzuki I, Takebayashi S, Misawa K, Ueda Y, Ichimura K: p27 Expression correlates with prognosis in patients with hypopharyngeal cancer. Anticancer Res 1999, 19:4407-4412

2. Masuda M, Hirakawa N, Nakashima T, Kuratomi Y, Komiyama S: Cyclin D1 overexpression in primary hypopharyngeal carcinomas. Cancer 1996, 78:390-395
3. Kohmura T, Hasegawa Y, Ogawa T, Matsuura H, Takahashi M Yanagita N, Nakashima T: Cyclin D1 and p53 overexpression predicts multiple primary malignant neoplasms of the hypopharynx and esophagus. Arch Otolaryngol Head Neck Surg 1999, 125:1351-1354

4. Frank JL, Bur ME, Garb JL, Kay S, Ware JL, Sismanis A, Neifeld JP: P53 tumor suppressor oncogene expression in squamous cell carcinoma of the hypopharynx. Cancer 1994, 73:181-186

5. Miyajima Y, Nakano R, Morimatsu M: Analysis of expression of matrix metalloproteinase-2 and -9 in hypopharyngeal squamous cell carcinoma by in situ hybridization. Ann Otol Rhinol Laryngol 1995, 104:678-684

6. Yu L, Lu S, Tian J, Ma J, Li J, Wang H, Xu W: TWIST expression in hypopharyngeal cancer and the mechanism of TWIST-induced promotion of metastasis. Oncol Rep 2012, 27:416-422

7. Kikkawa N, Hanazawa T, Fujimura L, Nohata N, Suzuki H, Chazono H, Sakurai D, Horiguchi S, Okamoto Y, Seki N: miR-489 is a tumour-suppressive miRNA target PTPN11 in hypopharyngeal squamous cell carcinoma (HSCC). Br J Cancer 2010, 103:877-884

8. Cromer A, Carles A, Millon R, Ganguli G, Chalmel F, Lemaire F, Young J, Demblee D, Thibault C, Muller D, Poch O, Abecassis J, Wasylyk B: Identification of genes associated with tumorigenesis and metastatic potential of hypopharyngeal cancer by microarray analysis. Oncogene 2004, 23:2484-2498

9. Steinhart H, Bohlender JE, Constantinidis J, Urbschat S, Fischer U, Iro $\mathrm{H}$, Pahl $\mathrm{S}$, Meese E: Genetic imbalances in preinvasive tissue of hypopharynx provide evidence for cytogenetic heterogeneity. Oncol Rep 2001, 8:1229-1231

10. Welkoborsky HJ, Bernauer HS, Riazimand HS, Jacob R, Mann WJ, Hinni ML: Patterns of chromosomal aberrations in metastasizing and nonmetastasizing squamous cell carcinomas of the oropharynx and hypopharynx. Ann Otol Rhinol Laryngol 2000, 109:401-410

11. Lee JW, Hsiao WT, Lee KF, Sheu LF, Hsu HY, Hsu LP, Su B, Lee MS, Hsu YC, Chang CH: Widespread expression of prostate apoptosis response-4 in nasopharyngeal carcinoma. Head Neck 2010, 32:877-885

12. Sells SF, Wood DP Jr, Joshi-Barve SS, Muthukumar S, Jacob RJ, Crist SA, Humphreys S, Rangnekar VM: Commonality of the gene programs induced by effectors of apoptosis in androgen-dependent and -independent prostate cells. Cell Growth Differ 1994, 5:457-466

13. El-Guendy N, Zhao $\mathrm{Y}$, Gurumurthy $\mathrm{S}$, Burikhanov $\mathrm{R}$, Rangnekar VM: Identification of a unique core domain of Par-4 sufficient for selective apoptosis induction in cancer cells. Mol Cell Biol 2003, 23:5516-5525

14. Gurumurthy S, Goswami A, Vasudevan KM, Rangnekar VM: Phosphorylation of Par-4 by protein kinase A is critical for apoptosis Mol Cell Biol 2005, 25:1146-1161

15. Goswami A, Burikhanov R, de Thonel A, Fujita N, Goswami M, Zhao Y, Eriksson JE, Tsuruo T, Rangnekar VM: Binding and phosphorylation of Par-4 by Akt is essential for cancer cell survival. Mol Cell 2005, 20:33-44

16. Irby RB, Kline CL: Par-4 as a potential target for cancer therapy Expert Opin Ther Targets 2013, 17:77-87

17. Hebbar N, Wang C, Rangnekar VM: Mechanisms of apoptosis by the tumor suppressor Par-4. J Cell Physiol 2012, 227:3715-3721

18. Zhao Y, Burikhanov R, Brandon J, Qiu S, Shelton BJ, Spear B, Bondada S, Bryson S, Rangnekar VM: Systemic Par-4 inhibits nonautochthonous tumor growth. Cancer Biol Ther 2011, 12:152-157

19. Burikhanov R, Zhao Y, Goswami A, Qiu S, Schwarze SR, Rangnekar VM: The tumor suppressor Par-4 activates an extrinsic pathway for apoptosis. Cell 2009, 138:377-388

20. Wang BD, Kline CL, Pastor DM, Olson TL, Frank B, Luu T, Sharma AK, Robertson G, Weirauch MT, Patierno SR, Stuart JM, Irby RB, Lee NH: Prostate apoptosis response protein 4 sensitizes human colon cancer cells to chemotherapeutic 5-FU through mediation of an NF-KB and microRNA network. Mol Cancer 2010, 9:98

21. Chaudhry P, Singh M, Parent S, Asselin E: Prostate apoptosis response 4 (Par-4), a novel substrate of caspase-3 during apoptosis activation. Mol Cell Biol 2012, 32:826-839 
22. Cook J, Krishnan S, Ananth S, Sells SF, Shi Y, Walther MM, Linehan WM, Sukhatme VP, Weinstein MH, Rangnekar VM: Decreased expression of the pro-apoptotic protein Par-4 in renal cell carcinoma. Oncogene 1999, 18:1205-1208

23. Kögel D, Reimertz C, Mech P, Poppe M, Fruhwald MC, Engemann H, Scheidtmann KH, Prehn JH: Dlk/ZIP kinase-induced apoptosis in human medulloblastoma cells: requirement of the mitochondrial apoptosis pathway. Br J Cancer 2001, 85:1801-1808

24. Boehrer S, Chow KU, Puccetti E, Ruthardt M, Godzisard S, Krapohl A, Schneider B, Hoelzer D, Mitrou PS, Rangnekar VM, Weidmann E: Deregulated expression of prostate apoptosis response gene-4 in less differentiated lymphocytes and inverse expressional patterns of par-4 and bcl-2 in acute lymphocytic leukemia. Hematol J 2001, 2:103-107

25. Moreno-Bueno G, Fernandez-Marcos PJ, Collado M, Tendero MJ, Rodriguez-Pinilla SM, Garcia-Cao I, Hardisson D, Diaz-Meco MT, Moscat J, Serrano M, Palacios J: Inactivation of the candidate tumor suppressor Par-4 in endometrial cancer. Cancer Res 2007, 67: 1927-1934

26. Barradas M, Monjas A, Diaz-Meco MT, Serrano M, Moscat J: The downregulation of the pro-apoptotic protein Par-4 is critical for Rasinduced survival and tumor progression. EMBO J 1999, 18: 6362-6369

27. Nalca A, Qiu SG, El-Guendy N, Krishnan S, Rangnekar VM: Oncogenic Ras sensitizes cells to apoptosis by Par-4. J Biol Chem 1999, 274:29976-29983

28. García-Cao I, Duran A, Collado M, Carrascosa MJ, MartínCaballero J, Flores JM, Diaz-Meco MT, Moscat J, Serrano M: Tumor-suppression activity of the proapoptotic regulator Par4. EMBO Rep 2005, 6:577-583

29. Joshi J, Fernandez-Marcos PJ, Galvez A, Amanchy R, Linares JF, Duran A, Pathrose P, Leitges M, Cañamero M, Collado M, Salas C, Serrano M, Moscat J, Diaz-Meco MT: Par-4 inhibits Akt and suppresses Ras-induced lung tumorigenesis. EMBO J 2008, 27: $2181-2193$

30. Goswami A, Qiu S, Dexheimer TS, Ranganathan P, Burikhanov R, Pommier Y, Rangnekar VM: Par-4 binds to topoisomerase 1 and attenuates its DNA relaxation activity. Cancer Res 2008, 68: 6190-6198

31. Butler J, Rangnekar VM: Par-4 for molecular therapy of prostate cancer. Curr Drug Targets 2003, 4:223-230

32. Zhao Y, Burikhanov R, Qiu S, Lele SM, Jennings CD, Bondada S, Spear B, Rangnekar VM: Cancer resistance in transgenic mice expressing the SAC module of Par-4. Cancer Res 2007, 67:9276-9285

33. Ravikumar B, Futter M, Jahreiss L, Korolchuk VI, Lichtenberg M, Luo S, Massey DC, Menzies FM, Narayanan U, Renna M, JimenezSanchez M, Sarkar S, Underwood B, Winslow A, Rubinsztein DC: Mammalian macroautophagy at a glance. J Cell Sci 2009, 122: $1707-1711$

34. Kim DH, Sarbassov DD, Ali SM, King JE, Latek RR, ErdjumentBromage H, Tempst P, Sabatini DM: mTOR interacts with raptor to form a nutrient-sensitive complex that signals to the cell growth machinery. Cell 2002, 110:163-175

35. Ravikumar B, Sarkar S, Davies JE, Futter M, Garcia-Arencibia M, Green-Thompson ZW, Jimenez-Sanchez M, Korolchuk VI, Lichtenberg M, Luo S, Massey DC, Menzies FM, Moreau K, Narayanan U, Renna M, Siddiqi FH, Underwood BR, Winslow AR, Rubinsztein DC: Regulation of mammalian autophagy in physiology and pathophysiology. Physiol Rev 2010, 90:1383-1435

36. Mizushima N, Levine B: Autophagy in mammalian development and differentiation. Nature Cell Biol 2010, 12:823-830

37. Eskelinen EL: The dual role of autophagy in cancer. Curr Opin Pharmacol 2011, 11:294-300

38. Pattingre S, Tassa A, Qu X, Garuti R, Liang XH, Mizushima N, Packer M, Schneider MD, Levine B: Bcl-2 antiapoptotic proteins inhibit Beclin 1-dependent autophagy. Cell 2005, 122: 927-939
39. Maiuri MC, Le Toumelin G, Criollo A, Rain JC, Gautier F, Juin P, Tasdemir E, Pierron G, Troulinaki K, Tavernarakis N, Hickman JA, Geneste O, Kroemer G: Functional and physical interaction between Bcl-X(L) and a BH3-like domain in Beclin-1. EMBO J 2007, 26: $2527-2539$

40. Norman JM, Cohen GM, Bampton ET: The in vitro cleavage of the hAtg proteins by cell death proteases. Autophagy 2010, 6:1042-1056

41. Moscat J, Diaz-Meco MT: p62 At the crossroads of autophagy, apoptosis and cancer. Cell 2009, 137:1001-1004

42. Lee JW, Liu PF, Hsu LP, Chen PR, Chang CH, Shih WL: EBV LMP-1 negatively regulates expression and pro-apoptotic activity of Par-4 in nasopharyngeal carcinoma cells. Cancer Lett 2009, 279: 193-201

43. Kabeya Y, Mizushima N, Ueno T, Yamamoto A, Kirisako T, Noda T, Kominami E, Ohsumi Y, Yoshimori T: LC3, a mammalian homologue of yeast Apg8p, is localized in autophagosome membranes after processing. EMBO J 2000, 19:5720-5728

44. Shvets E, Fass E, Elazar Z: Utilizing flow cytometry to monitor autophagy in living mammalian cells. Autophagy 2008, 4:621-628

45. Lee JW, Lee KF, Hsu HY, Hsu LP, Shih WL, Chu YC, Hsiao WT, Liu PF: Protein expression and intracellular localization of prostate apoptosis response-4 (Par-4) are associated with apoptosis induction in nasopharyngeal carcinoma cell lines. Cancer Lett 2007, 257: 252-262

46. Mizushima N, Yoshimori T, Levine B: Methods in mammalian autophagy research. Cell 2010, 140:313-326

47. Mizushima N: Methods for monitoring autophagy. Int J Biochem Cell Biol 2004, 36:2491-2502

48. Wei Y, Pattingre S, Sinha S, Bassik M, Levine B: JNK1-mediated phosphorylation of Bcl-2 regulates starvation-induced autophagy. Mol Cell 2008, 30:678-688

49. Díaz-Meco MT, Municio MM, Frutos S, Sanchez P, Lozano J, Sanz L, Moscat J: The product of par-4, a gene induced during apoptosis, interacts selectively with the atypical isoforms of protein kinase C. Cell 1996, 86:777-786

50. Chang S, Kim JH, Shin J: p62 Forms a ternary complex with PKCל and PAR-4 and antagonizes PAR-4-induced PKC Lett 2002, 510:57-61

51. Mathew R, Karp CM, Beaudoin B, Vuong N, Chen G, Chen HY, Bray K, Reddy A, Bhanot G, Gelinas C, Dipaola RS, KarantzaWadsworth V, White E: Autophagy suppresses tumorigenesis through elimination of p62. Cell 2009, 137:1062-1075

52. Xia Z, Dickens M, Raingeaud J, Davis RJ, Greenberg ME: Opposing effects of ERK and JNK-p38 MAP kinases on apoptosis. Science 1995, 270:1326-1331

53. Tang G, Yue Z, Talloczy Z, Hagemann T, Cho W, Messing A, Sulzer DL, Goldman JE: Autophagy induced by Alexander diseasemutant GFAP accumulation is regulated by p38/MAPK and mTOR signaling pathways. Hum Mol Genet 2008, 17:1540-1555

54. Frödin M, Gammeltoft S: Role and regulation of $90 \mathrm{kDa}$ ribosomal S6 kinase (RSK) in signal transduction. Mol Cell Endocrinol 1999, 151:65-77

55. Ogier-Denis E, Pattingre S, El Benna J, Codogno P: Erk1/2-dependent phosphorylation of Galpha-interacting protein stimulates its GTPase accelerating activity and autophagy in human colon cancer cells. J Biol Chem 2000, 275:39090-39095

56. Shimizu S, Konishi A, Nishida Y, Mizuta T, Nishina H, Yamamoto A, Tsujimoto Y: Involvement of JNK in the regulation of autophagic cell death. Oncogene 2010, 29:2070-2082

57. Hughes JP, Staton PC, Wilkinson MG, Strijbos PJ, Skaper SD, Arthur JS, Reith AD: Mitogen and stress response kinase-1 (MSK1) mediates excitotoxic induced death of hippocampal neurones. J Neurochem 2003, 86:25-32

58. Xu ZX, Liang J, Haridas V, Gaikwad A, Connolly FP, Mills GB, Gutterman JU: A plant triterpenoid, avicin D, induces autophagy by activation of AMP-activated protein kinase. Cell Death Differ 2007, 14:1948-1957 
59. Benbrook DM, Masamha CP: The pro-survival function of Akt kinase can be overridden or altered to contribute to induction of apoptosis. Curr Cancer Drug Targets 2011, 11:586-599

60. Yang W, Ju JH, Lee KM, Nam K, Oh S, Shin I: Protein kinase B/Akt1 inhibits autophagy by down-regulating UVRAG expression. Exp Cell Res 2013, 319:122-133

61. Romeo Y, Zhang X, Roux PP: Regulation and function of the RSK family of protein kinases. Biochem J 2012, 441:553-569

62. Johnstone RW, See RH, Sells SF, Wang J, Muthukkumar S, Englert C, Haber DA, Licht JD, Sugrue SP, Roberts T, Rangnekar VM, Shi Y: A novel repressor, par-4, modulates transcription and growth suppression functions of the Wilms' tumor suppressor WT1. Mol Cell Biol 1996, 16:6945-6956

63. Korolchuk VI, Saiki S, Lichtenberg M, Siddiqi FH, Roberts EA, Imarisio S, Jahreiss L, Sarkar S, Futter M, Menzies FM, O’Kane CJ, Deretic V, Rubinsztein DC: Lysosomal positioning coordinates cellular nutrient responses. Nat Cell Biol 2011, 13:453-460

64. Kroemer G, Levine B: Autophagic cell death: the story of a misnomer. Nat Rev Mol Cell Biol 2008, 9:1004-1010

65. Yu L, Alva A, Su H, Dutt P, Freundt E, Welsh S, Baehrecke EH, Lenardo MJ: Regulation of an ATG7-beclin 1 program of autophagic cell death by caspase-8. Science 2004, 304:1500-1502

66. Shimizu S, Kanaseki T, Mizushima N, Mizuta T, ArakawaKobayashi S, Thompson CB, Tsujimoto Y: Role of Bcl-2 family proteins in a non-apoptotic programmed cell death dependent on autophagy genes. Nat Cell Biol 2004, 6:1221-1228

67. Gump JM, Thorburn A: Autophagy and apoptosis: what is the connection? Trends Cell Biol 2011, 21:387-392
68. Wirawan E, Vande Walle L, Kersse K, Cornelis S, Claerhout S, Vanoverberghe I, Roelandt R, De Rycke R, Verspurten J, Declercq W, Agostinis $\mathrm{P}$, Vanden Berghe $\mathrm{T}$, Lippens $\mathrm{S}$, Vandenabeele P: Caspase-mediated cleavage of Beclin-1 inactivates Beclin-1-induced autophagy and enhances apoptosis by promoting the release of proapoptotic factors from mitochondria. Cell Death Dis 2010, 1:e18

69. Yousefi S, Perozzo R, Schmid I, Ziemiecki A, Schaffner T, Scapozza L, Brunner T, Simon HU: Calpain-mediated cleavage of Atg5 switches autophagy to apoptosis. Nat Cell Biol 2006, 8: 1124-1132

70. Betin VM, Lane JD: Caspase cleavage of Atg4D stimulates GABARAP-L1 processing and triggers mitochondrial targeting and apoptosis. J Cell Sci 2009, 122:2554-2566

71. Levine B, Sinha S, Kroemer G: Bcl-2 family members: dual regulators of apoptosis and autophagy. Autophagy 2008, 4:600-606

72. McEwan DG, Dikic I: The three musketeers of autophagy: phosphorylation, ubiquitylation and acetylation. Trends Cell Biol 2011, 21:195-201

73. Luo S, Garcia-Arencibia M, Zhao R, Puri C, Toh PP, Sadiq O, Rubinsztein DC: Bim inhibits autophagy by recruiting Beclin 1 to microtubules. Mol Cell 2012, 47:359-370

74. Michaud M, Martins I, Sukkurwala AQ, Adjemian S, Ma Y, Pellegatti P, Shen S, Kepp O, Scoazec M, Mignot G, Rello-Varona S, Tailler M, Menger L, Vacchelli E, Galluzzi L, Ghiringhelli F, di Virgilio F, Zitvogel L, Kroemer G: Autophagy-dependent anticancer immune responses induced by chemotherapeutic agents in mice. Science 2011, 334:1573-1577 